Issues in Information Systems

Volume 18, Issue 4, pp. 27-36, 2017

\title{
CONSUMER AND PROVIDER: ROLES TO UNDERSTAND CONTINUED USE BEHAVIOR IN VIRTUAL COMMUNITIES
}

\author{
Edgardo R. Bravo, Universidad del Pacifico-Lima-Peru, er.bravoo@up.edu.pe \\ Karina Ferreyra, Universidad del Pacifico-Lima-Peru, mk.ferreyrac@up.edu.pe \\ Christian Libaque-Saenz, Universidad del Pacifico-Lima-Peru, cf.libaques@up.edu.pe
}

\begin{abstract}
The increasing use of virtual communities makes research in this technology vital to understand the dynamics that users establish around them. In this sense, the virtual communities' literature recognizes that an individual has at least two behaviors in a virtual community: consumer and provider. The present research proposes a conceptual model where continued usage - in the context of virtual communities, specifically of social networks - is conceptualized as a multidimensional construct formed by the continued consumption and the continued information sharing. It also considers that these dimensions are distinguishable from each other and are due to different factors. This approach is expected to provide a more complete perspective on the roles of users within a virtual community. Likewise, it is expected that it will be able to provide bases for strategies for the continued existence of virtual communities.
\end{abstract}

Keywords: Information systems, IS continuance, social networks, information sharing

\section{INTRODUCTION}

The growth of social networks has been vertiginous in the last decade. According to the Pew Research Center, the use of social networking sites (SNS) by American adults has grown from 7\% to 65\% (number of individuals) in the last decade. This is reflected in a daily use of social networks, where Facebook is used every day by $70 \%$ of internet users and Instagram by $49 \%$ of them (Duggan, Ellison, Lampe, Lenhart, \& Madden, 2015).

Moreover, SNS have impacted the lives of individuals, organizations and society as a whole. Individuals use SNS for different purposes (e.g. making friends, sharing information, accessing entertainment, etc.). At an organizational level, SNS serve to connect employees, customers and suppliers; or to share information and participate in business processes without the need for physical presence. At a society level, SNS serve to connect citizens so that they can share information and collaborate on diverse initiatives such as the financing of risk projects, social mobilization, etc. (Ngai, Tao, \& Moon, 2015). Despite the advances in recent years in understanding this topic, Ngai, Moon, Lam, Chin, and Tao (2015) consider the research on these issues is still in the early stages. Therefore, they suggest the need for both conceptual and empirical contributions in this context.

Literature related to information systems (IS) has studied social networks. This literature states that once a technology has been adopted (in this case, a social network), the managers of this technology are interested in its continued use. Therefore, IS literature has focused on explaining this behavior called "continuance use", distinguishing it from "adoption" behavior (Bhattacherjee, 2001; Jasperson, Carter, \& Zmud, 2005). Several models in the literature have explained this behavior (Bhattacherjee, 2001; Hong, Thong, \& Tam, 2005); however, Bhattacherjee (2001)'s model, and its most recent update proposed by Bhattacherjee and Lin (2014), have become the most solidly established in the field (Hossain \& Quaddus, 2012). According to these models, the intention to continue using a technology is explained by satisfaction with previous experience of use and perceived usefulness. At the same time, these constructs are explained by the confirmation of expectations (in relation to the use experience). It should be noted that this model considers continuance behavior as the "continued consumption" of a technology, since it has its origins in the ExpectationConfirmation Theory (Oliver, 1980).

In that sense, previous studies that have applied this model in the context of virtual communities (e.g. social networks), have not questioned the orientation focused on consumption. Some papers have applied this model to different contexts with small theoretical changes (e.g. Tang \& Chiang, 2010). Other studies have added endogenous constructs or exogenous 


\section{Issues in Information Systems \\ Volume 18, Issue 4, pp. 27-36, 2017}

antecedents (Casaló, Flavián, \& Guinalíu, 2010; Jin, Lee, \& Cheung, 2009; Kim, 2011). Furthermore, the model has been extrapolated to explain the provision of information (e.g. Cheung, Lee, \& Lee, 2013; Jin, Zhou, Lee, \& Cheung, 2013). However, it was not considered that both orientations imply different behaviors, and that they may, therefore, be affected by different factors.

In that sense, the literature about virtual communities recognizes that an individual has at least two behaviors in a virtual community: consumer and provider. An individual consumes information by asking for information or asking questions for help, and the individual contributes by answering questions from others or initiating or participating in a discussion (Zheng, Zhao, \& Stylianou, 2013). Moreover, it is recognized that there are varying degrees of involvement with the community, from only consumers to committed participants, who not only contribute but also provide to the community (Blanchard, 2008; Wang \& Fesenmaier, 2004). The distinction between consumer/provider is also found in other types of technologies. For example, in the context of knowledge management systems, He and Wei (2009) distinguish two behaviors: (1) to contribute with knowledge and (2) to seek for knowledge, which have different causal networks.

Research oriented to the role of the provider often appeals to theoretical frameworks different from Bhattacherjee (2001). In that sense, Social Capital Theory, in the context of virtual communities, has been used to explain why people contribute to or collaborate with other members of a virtual community. Chiu, Hsu, and Wang (2006) consider this role as an active behavior that is reflected in the intention to share information. This intention is measured through the quantity and quality of knowledge shared in that context. Social interaction, reciprocity, identification with the community, trust among members, shared language, shared vision within the community, and community benefit expectations are among the antecedents of this behavior (Chang \& Chuang, 2011; Chiu et al., 2006).

In this way, it is suggested that the individual participates in a virtual community through two roles: consumer and provider. However, the research lines have explained continuance behavior (1) without distinguishing the consumer and provider role, (2) considering only the role of provider (information sharing) or (3) considering only the role of consumer (information seeking).

To bridge this gap in the literature, this research proposes a conceptual model where: (1) the continuance behavior - in the context of virtual communities, specifically of SNS - is conceptualized as a multidimensional construct formed by the continued use in each role and (2) that these dimensions are distinguishable from each other and are due to different factors.

On a theoretical level, it is hoped that this research will provide a conceptual framework that improves the understanding of existing roles within a virtual community. Thus, the notion of "continuance use" would be expanded by considering a passive dimension of behavior (consumption) and an active dimension (of contribution and/or participation). On a practical level, it would help the managers of the platforms where these communities develop to establish guidelines or strategies for the survival of a community, encouraging not only the consumption of information, but also participation in it.

To this end, the article is structured as follows: first, we present a literature review where a virtual community is defined, as well as the roles of the consumer and the provider through the theories mentioned, then, we establish the research model to be evaluated and, finally, we present the tentative methodology of the research.

\section{THEORETICAL BACKGROUND}

This section includes the literature review about virtual communities, the model of continued use proposed by Bhattacherjee (2001) and the model of social capital in the behavior of information formulated by Chiu et al. (2006).

\section{Virtual communities}

A virtual community is an online social network in which individuals, with common interests and needs, interact repeatedly in an organized way for the final purpose of sharing information and engaging in social dynamics (C.-J. Chen \& Hung, 2010; Chiu et al., 2006; Kosonen, 2009). Being focused on communication and interaction among its members, a virtual community generates specific knowledge that allows the individuals the execution of common functions, besides 
learning and/or contributing to that knowledge (C.-J. Chen \& Hung, 2010; Hsu, Ju, Yen, \& Chang, 2007). In addition, this interaction involves different levels of involvement, determining passive and active roles among its members (Blanchard, 2008; Chiu et al., 2006).

Thus, a recurrent theme of study in the literature of virtual communities is the type of members that belong to them and how, through their behavior, they influence the success of a virtual community. The success of a virtual community is understood as the ability to sustain itself over time, while meeting the needs of its members and maintaining that satisfaction (Blanchard, 2008). In this way, we have the leaders, who provide help and assistance to other members; the participants, who actively contribute to communications and interactions between members; and the lurkers, those who simply read the messages, and do not offer any other kind of contribution (Blanchard, 2008). For the purpose of the present investigation, we will focus on the passive behaviors (of consumption) and active behaviors (of sharing) evidenced in the lurkers and participants, respectively.

\section{Model of continued use of virtual communities}

In the context of IS, many researches point out that the success of the system or technology depends on their use continuance, beyond initial use or adoption (p.e. Bhattacherjee, 2001; Jin, Cheung, Lee, \& Chen, 2009). Thus, Bhattacherjee (2001)'s model of IS continuance is important because it considers post-adoption factors that would explain the use continuance or the abandonment of a technology or IS after its adoption.

This model has its origins in the Expectation-Confirmation Theory (Oliver, 1980) and suggests that the intention of continuance use or consumption of an IS is explained by satisfaction with previous consumption and by its perceived usefulness; which, in turn, are explained by the confirmation of expectations in relation to that consumer experience. Satisfaction is considered an affective or emotional response to the use of a technology (Zheng et al., 2013). A satisfactory experience in the use of an IS is required for the purpose of use continuance (Bhattacherjee, 2001; Cheung et al., 2013). Perceived usefulness represents post-use beliefs and expectations about the effectiveness and benefits of an IS (Bhattacherjee, 2001; Zheng et al., 2013) ; and the confirmation is the congruence between the expectations prior and after the use, confirming (or not) expected performance (Jin et al., 2013). In this sense, the model explains how users evaluate their use experience and how that assessment affects their decision to continue using an IS (Jin, Cheung, et al., 2009).

\section{Social capital theory in virtual communities}

As mentioned, members of a virtual community have different roles within it. One of them is an active role evidenced in behaviors of information sharing. The members of a virtual community not only seek to interact socially among themselves, but also, from that interaction, they look for information or knowledge to solve problems, to be informed, to learn, etc. (Chiu et al., 2006). Thus, they accumulate and integrate information and experiences provided by their members, and maintain a level of active exchange when the perceived benefit of sharing information is greater than the perceived loss of knowledge (Chang \& Chuang, 2011).

The literature of information sharing takes as a special reference the Social Capital Theory. Social capital refers to the goods or resources framed within networks of relationships between individuals, communities or societies, and exists through interpersonal relationships between individuals and connections with their communities (Chang \& Chuang, 2011; Nahapiet \& Ghoshal, 1998). Thus, social capital is believed to be the key mechanism for creating and sharing knowledge (Chai, Das, \& Rao, 2011; Inkpen \& Tsang, 2005; Nahapiet \& Ghoshal, 1998).

In the context of virtual communities, the approach of Chiu et al. (2006) has been used to explain why people contribute or collaborate with other members of a virtual community. Integrating the Social Capital and Social Cognition Theories, it is proposed that the intention to share information is reflected through two variables: the quantity and quality of information or knowledge shared. From the first theory, it takes the dimensions proposed by Nahapiet and Ghoshal (1998), these are the constructs of social interaction (structural dimension), trust, reciprocity and identification (relational dimension); and the shared language and vision (cognitive dimension). From the second theory, it takes the expectations of results, especially at a community level. All of these factors are important in information-sharing behavior (Chang \& Chuang, 2011; Chiu et al., 2006). 


\section{RESEARCH MODEL}

As mentioned, virtual communities are made up of a group of individuals who communicate regularly through a technological medium, in an organized and constant way (C.-J. Chen \& Hung, 2010; Hsu et al., 2007). In this way, interaction dynamics are generated between members that show different roles in the use of a virtual community.

For the purposes of this research, the proposed model investigates both the passive role (of information consumption) and the active role (of information sharing), which would determine the intention to continue using a virtual community.

\section{Continuance consuming of information in virtual communities}

The passive role in the context of virtual communities refers to those behaviors that are limited to the consumption of available information. In this sense, the model for IS continuance use proposed by Bhattacherjee (2001) is pertinent since the intention to continue using an IS can be understood as the consumption of information in the context of virtual communities.

In the first place, the IS literature defines satisfaction as the affections that arise after its use, which are the results of a cognitive evaluation of the confirmation (or otherwise) of the expectations about its performance (Bhattacherjee, 2001; Jin, Lee, \& Cheung, 2010). Thus, the satisfaction of the prior use of a technology is considered as an important antecedent in the intention of continued use (Bhattacherjee, 2001). The empirical evidence supporting this relationship is sufficient (Bhattacherjee, 2001; I. Chen, 2007; Cheung \& Lee, 2007; Jin et al., 2010). Also, in the context of virtual communities, there is evidence about the key role that satisfaction of prior use plays in continued use, especially from the role of information consumption (p.e. Jin, Cheung, et al., 2009; Tang \& Chiang, 2010).

For the purposes of the present investigation, satisfaction is defined as the affections of the prior use of a virtual community, in terms of the information obtained through it, and that are derived from the evaluation of expectations of its members in terms of their performance. Thus, if individuals are satisfied with the information obtained in their community, they are more likely to continue using it. Thus, the following hypothesis is proposed:

H1: Satisfaction positively affects the intention to continue consuming information.

Also, within the IS continuance use model proposed by Bhattacherjee (2001), a determining factor in the continuance intention of an IS is the perceived usefulness. This is defined as the belief that using an IS helps to improve individual's performance and achieve their goals (Davis, 1989). Thus, it influences the formation of behavioral intentions since productivity is associated with that behavior (Casaló et al., 2010; Davis, 1989). This relationship is supported by several research of IS continuance (Bhattacherjee, 2001; S.-C. Chen, Liu, \& Lin, 2013; M. Limayem, S. G. Hirt, \& C. M. Cheung, 2007a), and virtual communities (p.e. Jin, Cheung, et al., 2009; Tang \& Chiang, 2010).

It is important to mention that, in the context of consumption and adoption of information, Sussman and Siegal (2003) consider perceived usefulness as the degree of information perceived as valuable. Considering the role of consumption present in the members of virtual communities, for the purposes of this research, it is considered that the perceived usefulness of a virtual community is given based on the information collected by its members. In that sense, to the extent that individuals perceive the information obtained as being useful, they will have a greater intention to continue consuming information from their community. Therefore, the following hypothesis is proposed:

$\mathrm{H} 2$ : Perceived usefulness positively affects the intention to continue consuming information.

Likewise, perceived usefulness would also be positively related to satisfaction. Thus, Bhattacherjee (2001) argues that to the extent that an IS is perceived as useful, the individual will feel more satisfied with the technology. Research in this context argues that perceived usefulness is a factor that consistently influences the post-acceptance affections of an IS (satisfaction) (Bhattacherjee, 2001; Casaló et al., 2010). Thus, in the context of this research, the fact that information obtained from a community is perceived as useful by the members of a virtual community, generates satisfaction with its use (Jin, Cheung, et al., 2009). Hence, the following hypothesis is proposed:

H3: Perceived usefulness positively affects satisfaction. 


\section{Issues in Information Systems \\ Volume 18, Issue 4, pp. 27-36, 2017}

Confirmation is the extent to which pre-use expectations are congruent with the performance of an IS. Therefore, it is a cognitive evaluation of a technology in the post-adoption stage (Bhattacherjee, 2001; Kim, 2011). This is taken from the Theory of Cognitive Dissonance (Festinger, 1962), which argues that an individual experiences dissonance when their previous expectations are higher than the perception of performance after the use of a technology, so that they are disconfirmed. On the other hand, when user expectations are exceeded by perceived performance, they are positively confirmed. Thus, as confirmation of expectations is related to the perceived performance of an IS, it is established that it is related to its perceived usefulness (Bhattacherjee, 2001; Limayem et al., 2007a).

In the literature about virtual communities, it is evident that the confirmation of expectations about a virtual community has a positive impact on their perceived usefulness (p.e. Jin et al., 2013). For the purposes of this research, it is expected that confirmation of expectations favors the perception of how useful the information consumed or obtained from the community is. In this sense, it is proposed:

H4: Confirmation of expectations positively affects perceived usefulness.

In that line, confirmation of expectations would also be related to the individual's satisfaction. In the IS context, when the performance of a technology surpasses the user's expectations, these are confirmed positively and therefore, the individual is more satisfied with the technology usage (Bhattacherjee, 2001). This relationship has been demonstrated empirically, even in the context of virtual communities with the consumption role of the participant (p.e.Kim, 2011). Thus, it is considered that the confirmation of expectations generated prior to the acquisition of information from a virtual community (and therefore of its use), makes its members feel more satisfied, and the following hypothesis is considered:

H5: Confirmation of expectations positively affects satisfaction.

\section{Continuance of sharing information in virtual communities}

Members of a virtual community also exhibit active behaviors through information sharing or exchange of knowledge. Therefore, the Social Capital Theory (Chiu et al., 2006) proves to be important because it gives a conceptual framework to understand the inherent resources in a virtual community that are going to encourage those behaviors (Chiu et al., 2006).

In the context of virtual communities, Chiu et al. (2006) apply and validate a model that combines both Social Capital Theory and Social Cognitive Theory. First, the authors argue that trust among members is an important antecedent to the intention of sharing information. Trust is understood as the beliefs about the integrity of members of a virtual community, in relation to how they follow the set of accepted values, norms and principles within the community (Chiu et al., 2006). In this way, when members trust each other, they are less concerned about being deceived and they are more involved in the dynamics of collaboration and participation (Nahapiet \& Ghoshal, 1998).

From the organizational literature, trust is conceived as a precondition for the effective exchange of knowledge among individuals (Nonaka, 1994). From the literature about virtual communities, empirical evidence is also found about the exchange relationship of trust and the intention of sharing information (p.e.Chai et al., 2011; Chang \& Chuang, 2011; Chiu et al., 2006).

Based on the above, this research considers that trust among the members of a virtual community generates greater dynamics of information exchange, and, therefore, the intention to continue sharing information or knowledge in it. Therefore, the following hypothesis is proposed:

H6: Trust positively affects the intention to continue sharing information.

Norms of reciprocity are also considered important for the exchange of information within a virtual community. Chiu et al. (2006) define these as those exchanges of information that are mutual and perceived as fair among members. In this way, members expect to be rewarded in the same way they provide something (in this case, information). Similarly, the establishment of norms of cooperation is useful for the creation of intellectual capital (Nahapiet \& Ghoshal, 1998), which is typical of the interaction dynamics in a virtual community.

Previous research finds that individuals who cooperate with others under a desire for equality and reciprocity are more likely to have positive attitudes about sharing information, and this affects the intention to share information (Bock, Zmud, Kim, \& Lee, 2005). In the context of virtual communities, there is also evidence of a positive relationship between reciprocity and the intention to share information (p.e. Chai et al., 2011; Chang \& Chuang, 2011). Thus, the following hypothesis is proposed: 


\section{Issues in Information Systems \\ Volume 18, Issue 4, pp. 27-36, 2017}

H7: Reciprocity positively affects the intention to continue sharing information.

In the context of a virtual community, social interaction ties represent the strength of the relationships among members, the amount of time invested, and the frequency of communication between them (Chiu et al., 2006). To the extent that social bonds are strong and balanced, relationships between them will be healthy and this will lead to members engaging in interpersonal activities (Nahapiet \& Ghoshal, 1998), such as information sharing. In this sense, social interaction ties are channels for resources and information within a community to flow among participants (Tsai \& Ghoshal, 1998), so they become a means of accessing broad sources of knowledge (Chiu et al., 2006).

Empirical evidence shows that an individual who is central to these bonds has greater potential in combining and exchanging resources with other actors (Inkpen \& Tsang, 2005). Also, in the context of information exchange, the stronger the ties, the greater the intensity, as well as the frequency and breadth of the shared information (Yli-Renko, Autio, \& Sapienza, 2001). From virtual community literature, there is evidence of the relationship between social interaction ties and the intention to share information (p.e. Chai et al., 2011; Yoon \& Wang, 2011). Thus, to the extent that the ties between members are greater, the probability of sharing or exchanging information in a virtual community will be greater. Therefore, the following should be stated:

H8: Social interaction ties positively affect the intention to continue sharing information.

The Social Capital Theory proposes that having shared resources (e.g. shared vision) helps to establish bonds in the members of a community. Thus, (Tsai \& Ghoshal, 1998) consider that a shared vision reflects the collective goals and aspirations of the members of an organization. In that sense, this is a mechanism that connects the members of a community and makes them more likely to share or exchange resources. The union between the members generates a mutual understanding that allows also the exchange of ideas (Inkpen \& Tsang, 2005).

From the literature of virtual communities, Chiu et al. (2006) consider that a vision shared by the members of a virtual community helps them to know the meaning of behaviors like sharing information. This also improves and increases the quality and quantity of the shared information. Empirical research supports the relationship between shared vision and the intention to share information (Liao \& Chou, 2012; Yoon \& Wang, 2011). Literature has found that interpersonal communication is more likely to occur among friends who already know each other in off line context. Therefore offline ties can facilitate stronger online ties (Lee, Park, Na, \& Kim, 2016). Consequently, it is possible to propose the following hypothesis:

H9: Shared vision positively affects the intention of continuing to share information.

\section{Continued usage of virtual communities}

Finally, based on the above, the intention to consume and share information are behaviors that could potentially influence the overall continued use of a virtual community. First, the IS continuance suggests that the continued use of a technology is given by its consumption. In the case of a virtual community, this is reflected from the recurrent consumption of information seen in it. On the other hand, the literature on information sharing in the context of virtual communities suggests that continued information sharing could inherently help in the continuance of a virtual community. In this way, the following hypotheses are considered:

H10: The intention to continue consuming information positively affects the virtual community continuance intention. H11: The intention to continue sharing information positively affects the virtual community continuance intention. 
Issues in Information Systems

Volume 18, Issue 4, pp. 27-36, 2017

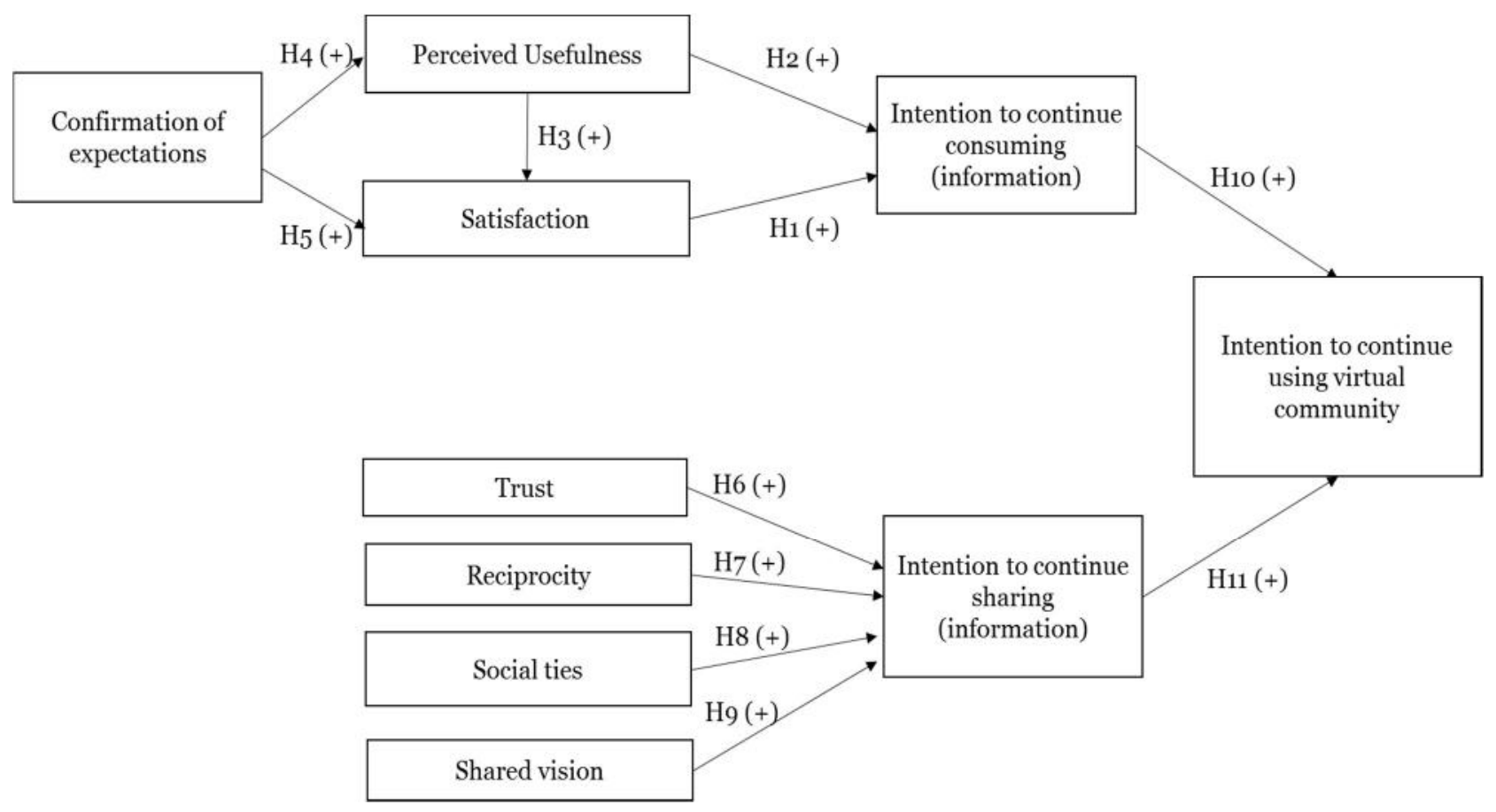

Figure 1. Research Model

\section{RESEARCH METHOD}

Since this study is an ongoing research, this section describes the procedures to be followed for data collection and analysis.

\section{Measurement Instrument}

The constructs related to the ECM-IT as intention of continuance consumption, perceived usefulness, satisfaction and confirmation of expectations will be measured with items based on the work of M. Limayem, S. G. Hirt, and C. M. K. Cheung (2007b); Zheng et al. (2013). On the other hand, the variables related to Social Capital Theory as intention to continue sharing information, trust, reciprocity, social interaction ties and shared vision will be evaluated with scales used by Chiu et al. (2006), Lin, Hung, and Chen (2009), and Liao and Chou (2012). Finally, continuance use intention of a virtual community will be evaluated with items based on the work of Bhattacherjee (2001).

\section{Data Collection (Future Step)}

Data collection will be via a survey and structural equation models with SPSS AMOS 19 will be used for data analysis. The sample will be chosen from users of a cloud storage technology. The data will be collected through Amazon Mechanical Turk, which is a web-based platform where employers (called requesters) post outsourced tasks for an anonymous network of laborers (called workers) who receive compensation for their contribution (Steelman, Hammer, \& Limayem, 2014). This website has proven to be effective in data collection (Steelman et al., 2014). A pilot test will first be conducted to check the reliability and validity of our measurement items. To determine the minimum sample size, we follow (Chin, 1998)'s rule-of-thumb which establishes that a sample size should be at least 10 times (1) the largest number of formative indicators or (2) the largest number of independent variables impacting a dependent variable, whichever is greater. We expect to collect 200 valid responses, which is more than adequate for estimation procedures. 


\section{Issues in Information Systems \\ Volume 18, Issue 4, pp. 27-36, 2017}

\section{IMPLICATIONS (EXPECTED)}

For Theory, our research attempts to explain the continued use of a virtual community based on the interaction of its users in terms of consumption and information sharing. Thus, it is hoped that this approach will contribute to the theoretical understanding of the dynamics that are constituted within a virtual community.

Also, at a practical level, managers are expected to give importance to the way their users use a virtual community. The results can provide a greater degree of granularity from the evaluation of the two types of behaviors that can contribute to the formation of continued use. Thus, strategies that help in the long-term permanence and use of the community over time can be evaluated.

\section{REFERENCES}

Bhattacherjee, A. (2001). Understanding information systems continuance: An expectation-confirmation model. MIS Quarterly, 25(3), 351-370.

Bhattacherjee, A., \& Lin, C.-P. (2014). A unified model of IT continuance: Three complementary perspectives and crossover effects. European Journal of Information Systems, 24(4), 1-10.

Blanchard, A. L. (2008). Definition, antecedents, and outcomes of successful virtual communities. The Encyclopedia of e-Collaboration.

Bock, G.-W., Zmud, R. W., Kim, Y.-G., \& Lee, J.-N. (2005). Behavioral intention formation in knowledge sharing: Examining the roles of extrinsic motivators, social-psychological forces, and organizational climate. MIS Quarterly, 87-111.

Casaló, L. V., Flavián, C., \& Guinalíu, M. (2010). Antecedents and Consequences of Consumer Participation in Online Communities: The Case of the Travel Sector. [Article]. International Journal of Electronic Commerce, 15(2), 137-167. doi: DOI 10.2753/JEC1086-4415150205

Chai, S., Das, S., \& Rao, H. R. (2011). Factors affecting bloggers' knowledge sharing: An investigation across gender. Journal of Management Information Systems, 28(3), 309-342.

Chang, H. H., \& Chuang, S.-S. (2011). Social capital and individual motivations on knowledge sharing: Participant involvement as a moderator. Information \& Management, 48(1), 9-18.

Chen, C.-J., \& Hung, S.-W. (2010). To give or to receive? Factors influencing members' knowledge sharing and community promotion in professional virtual communities. Information \& Management, 47(4), 226-236.

Chen, I. (2007). The factors influencing members' continuance intentions in professional virtual communities-a longitudinal study. Journal of Information Science.

Chen, S.-C., Liu, M.-L., \& Lin, C.-P. (2013). Integrating technology readiness into the expectation-confirmation model: An empirical study of mobile services. Cyberpsychology, Behavior, and Social Networking, 16(8), 604-612.

Cheung, C. M., \& Lee, M. K. (2007). What drives members to continue sharing knowledge in a virtual professional community? The role of knowledge self-efficacy and satisfaction Knowledge Science, Engineering and Management (pp. 472-484): Springer.

Cheung, C. M., Lee, M. K., \& Lee, Z. W. (2013). Understanding the continuance intention of knowledge sharing in online communities of practice through the post-knowledge-sharing evaluation processes. Journal of the American Society for Information Science and Technology, 64(7), 1357-1374.

Chin, W. W. (1998). The partial least squares approach to structural equation modeling. Modern methods for business research, 295(2), 295-336. 
Chiu, C.-M., Hsu, M.-H., \& Wang, E. T. (2006). Understanding knowledge sharing in virtual communities: An integration of social capital and social cognitive theories. Decision Support Systems, 42(3), 1872-1888.

Davis, F. D. (1989). Perceived usefulness, perceived ease of use, and user acceptance of information technology. MIS Quarterly, 319-340.

Duggan, M., Ellison, N. B., Lampe, C., Lenhart, A., \& Madden, M. (2015). Frequency of Social Media Use. Retrieved from http://www.pewinternet.org/2015/01/09/frequency-of-social-media-use-2/

Festinger, L. (1962). A theory of cognitive dissonance (Vol. 2): Stanford university press.

He, W., \& Wei, K.-K. (2009). What drives continued knowledge sharing? An investigation of knowledge-contribution and-seeking beliefs. Decision Support Systems, 46(4), 826-838.

Hong, S.-J., Thong, J., \& Tam, K.-Y. (2005). Understanding continued IT usage: An extension to the expectationconfirmation model in IT domain. PACIS 2005 Proceedings, 105.

Hossain, M. A., \& Quaddus, M. (2012). Expectation-confirmation theory in information system research: A review and analysis. In Y. K. Dwivedi, M. R. Wade \& S. L. Schneberger (Eds.), Information systems theory: Explaining and predicting our digital society, Vol 1. (pp. 441-469). New York: Springer.

Hsu, M.-H., Ju, T. L., Yen, C.-H., \& Chang, C.-M. (2007). Knowledge sharing behavior in virtual communities: The relationship between trust, self-efficacy, and outcome expectations. International journal of human-computer studies, 65(2), 153-169.

Inkpen, A. C., \& Tsang, E. W. (2005). Social capital, networks, and knowledge transfer. Academy of management review, 30(1), 146-165.

Jasperson, J. S., Carter, P. E., \& Zmud, R. W. (2005). A comprehensive conceptualization of post-adoptive behaviors associated with information technology enabled work systems. MIS Quarterly, 29(3), 525-557.

Jin, X.-L., Cheung, C. M., Lee, M. K., \& Chen, H.-P. (2009). How to keep members using the information in a computer-supported social network. Computers in Human Behavior, 25(5), 1172-1181.

Jin, X.-L., Lee, M. K., \& Cheung, C. M. (2009). Understanding users' continuance intention to answer questions in online question answering communities. Paper presented at the Proceedings of The 9th International Conference on Electronic Business. Macau.

Jin, X.-L., Lee, M. K., \& Cheung, C. M. (2010). Predicting continuance in online communities: model development and empirical test. Behaviour \& Information Technology, 29(4), 383-394.

Jin, X.-L., Zhou, Z., Lee, M. K., \& Cheung, C. M. (2013). Why users keep answering questions in online question answering communities: A theoretical and empirical investigation. International Journal of Information Management, 33(1), 93-104.

Kim, B. (2011). Understanding antecedents of continuance intention in social-networking services. Cyberpsychology, Behavior, and Social Networking, 14(4), 199-205.

Kosonen, M. (2009). Knowledge sharing in virtual communities-a review of the empirical research. International Journal of Web Based Communities, 5(2), 144-163.

Lee, J. Y., Park, S., Na, E.-Y., \& Kim, E.-m. (2016). A comparative study on the relationship between social networking site use and social capital among Australian and Korean youth. Journal of Youth Studies, 19(9), 1164-1183. 
Liao, S., \& Chou, E.-y. (2012). Intention to adopt knowledge through virtual communities: posters vs lurkers. Online Information Review, 36(3), 442-461.

Limayem, M., Hirt, S. G., \& Cheung, C. M. (2007a). How habit limits the predictive power of intention: The case of information systems continuance. MIS Quarterly, 705-737.

Limayem, M., Hirt, S. G., \& Cheung, C. M. K. (2007b). How habit limits the predictive power of intention: the case of information systems continuance. MIS Quarterly, 31(4), 705-737.

Lin, M.-J. J., Hung, S.-W., \& Chen, C.-J. (2009). Fostering the determinants of knowledge sharing in professional virtual communities. Computers in Human Behavior, 25(4), 929-939.

Nahapiet, J., \& Ghoshal, S. (1998). Social capital, intellectual capital, and the organizational advantage. Academy of management review, 23(2), 242-266.

Ngai, E. W., Moon, K.-1. K., Lam, S., Chin, E. S., \& Tao, S. S. (2015). Social media models, technologies, and applications: an academic review and case study. Industrial Management \& Data Systems, 115(5), 769-802.

Ngai, E. W., Tao, S. S., \& Moon, K. K. (2015). Social media research: Theories, constructs, and conceptual frameworks. International Journal of Information Management, 35(1), 33-44.

Nonaka, I. (1994). A dynamic theory of organizational knowledge creation. Organization science, 5(1), 14-37.

Oliver, R. L. (1980). A cognitive model of the antecedents and consequences of satisfaction decisions. [Article]. Journal of Marketing Research (JMR), 17(4), 460-469.

Steelman, Z. R., Hammer, B. I., \& Limayem, M. (2014). Data Collection in the Digital Age: Innovative Alterantives to Student Samples. MIS Quarterly, 38(2), 355-378.

Sussman, S. W., \& Siegal, W. S. (2003). Informational influence in organizations: An integrated approach to knowledge adoption. Information Systems Research, 14(1), 47-65.

Tang, J.-t. E., \& Chiang, C.-h. (2010). Integrating experiential value of blog use into the expectation-confirmation theory model. Social Behavior and Personality: an international journal, 38(10), 1377-1389.

Tsai, W., \& Ghoshal, S. (1998). Social capital and value creation: The role of intrafirm networks. Academy of Management Journal, 41(4), 464-476.

Wang, Y., \& Fesenmaier, D. R. (2004). Towards understanding members' general participation in and active contribution to an online travel community. Tourism management, 25(6), 709-722.

Yli-Renko, H., Autio, E., \& Sapienza, H. J. (2001). Social capital, knowledge acquisition, and knowledge exploitation in young technology-based firms. Strategic management journal, 22(6-7), 587-613.

Yoon, C., \& Wang, Z.-W. (2011). The role of citizenship behaviors and social capital in virtual communities. Journal of Computer Information Systems, 52(1), 106-115.

Zheng, Y., Zhao, K., \& Stylianou, A. (2013). The impacts of information quality and system quality on users' continuance intention in information-exchange virtual communities: An empirical investigation. Decision Support Systems, 56, 513-524. 